\title{
Investigation of the affective factors on the survival rate of patients with laryngeal cancer using Cox proportional hazards and Lin -Ying's additive hazards models
}

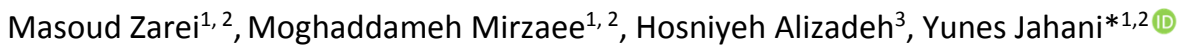 \\ Received: 10 May 2020 \\ Published: 2 Feb 2021
}

\section{Abstract}

Background: Determining the factors affecting survival and appropriate treatment methods leads to improving the survival rate and quality of life in cancer patients; therefore this study was aimed to determine the effective factors on the survival rate of patients with Laryngeal cancer in Kerman city, Iran.

Methods: This retrospective cohort study included 370 patients with Laryngeal cancer who referred to the hospitals of Kerman city, Iran during 2008 to 2018. Data were analyzed using Cox Proportional Hazards and Lin-Ying's Additive Hazards models. Data analysis was done using SAS software version 9.4. The P-value of less than 0.05 was considered as statistically significant.

Results: The mean age at the time of diagnosis was $58.16 \pm 10.60$ years. About $92 \%$ of the patients were men. The patient's $1,3,5,7$ and 10 -years of overall survival rates were equal to $82.38 \%, 60.68 \%, 55.98 \%, 49.83 \%$, and $30.91 \%$, respectively. Age at the diagnosis $(\mathrm{p}=0.001)$, radiotherapy $(\mathrm{p}=0.001)$, chemotherapy $(\mathrm{p}=0.015)$, surgery $(\mathrm{p}=0.031)$, and smoking $(\mathrm{p}=0.001)$ were found to have significant effect on the patient's survival rate in the Cox model. These variables were significant in the Lin-Ying model too.

Conclusion: Treatment is an important factor in controlling the disease and survival of cancer patients, and choosing the best treatment depends on the condition of the patient and the disease level.

Keywords: Survival analysis, Laryngeal cancer, Treatment, Hazard ratio, Excess risk

Conflicts of Interest: None declared

Funding: This study has been funded and supported by Kerman University of Medical Sciences (Project No: 97000151).

\section{*This work has been published under CC BY-NC-SA 1.0 license. \\ Copyright $\odot$ Iran University of Medical Sciences}

Cite this article as: Zarei M, Mirzaee M, Alizadeh H, Jahani Y. Investigation of the affective factors on the survival rate of patients with laryngeal cancer using Cox proportional hazards and Lin -Ying's additive hazards models. Med J Islam Repub Iran. 2021 (2 Feb);35:16. https://doi.org/10.47176/mjiri.35.16

\section{Introduction}

Cancer is the second prevalent cause of mortality in the developed countries and the third cause of death in developing countries. Regarding the increasing trend of cancer, the number of mortalities is expected to increase in future years (1). In 2018, about 18.1 million new cancer cases

Corresponding author: Dr Yunes Jahani, u.jahani@kmu.ac.ir

1. Modeling in Health Research Center, Institute for Futures Studies in Health, Kerman University of Medical Sciences, Kerman, Iran

2. Department of Biostatistics and Epidemiology, School of Public Health, Kerman University of Medical Sciences, Kerman, Iran

3. Physiology Research Center, Institute of Basic and Clinical Physiology Sciences, Kerman University of Medical Sciences, Kerman, Iran and 9.6 million deaths caused by cancer were reported from 185 countries (2). According to the report by the International Agency for Research on Cancer, 110115 new cases of cancer were estimated in Iran in 2018 (3). In 2012, about 84800 new cases of cancer were reported in

$\uparrow$ What is "already known" in this topic:

There has been no study using Lin-Ying's additive hazards model for investigation of the affective factors on the survival rate of patients with laryngeal cancer in Iran. Also, in recent years, there has been no study on the survival of laryngeal cancer and its treatment in Kerman, the largest southeastern city of Iran.

\section{$\rightarrow$ What this article adds:}

This study showed that Smoking after the diagnosis of cancer increases the risk of death. Treatments have a significant relationship with the survival of patients, so treatment is an important factor in controlling the disease and survival of cancer patients. 
Iran, that according to the predictions, it is estimated to reach about 129700 new cases of cancer in 2025 (4). Also, in 2014 about 2838 new cases of cancer were reported in Kerman province in Iran (5).

Head and neck cancers involve the area of the head or neck consisting of the sections such as the oral cavity, nose, pharynx, larynx, paranasal sinuses and nasal cavity, salivary glands, and thyroid. Laryngeal cancer is one of the most prevalent types of head and neck cancers (6). In 2018 , approximate number of cancer patients was estimated for 36 types of cancer in 185 countries, the results of which accounted for approximately 177422 new cases and 94771 deaths caused by laryngeal cancer (2). Laryngeal cancer is more common in men and its prevalence is higher in middle-age patients (7). The choice of appropriate treatment depends on several factors, including disease stage, tumor size, tumor location and patient condition (physical and mental). Treatment of laryngeal cancer includes radiotherapy, chemotherapy, surgery or a combination of treatments (8). The goal of treatment is controlling disease and increasing the survival rate of cancer patients as well as preserving the quality of life of patients in short- and long-term. Many cancer survivors, even those who enjoy a free treatment, should adapt themselves to the long-term effects of treatment and mental concerns, like fear of recurrence (9). Those patients who should be treated by total laryngectomy for treatment of laryngeal cancer, unfortunately completely lose their voice and their quality of life decreases in different dimensions (10). Therefore, preserving the larynx is the most important concern for laryngeal cancer patients. As a result, radiotherapy and chemotherapy are considered the most important treatment methods (11). During the recent 20 years, huge advancements have occurred regarding the diagnosis and treatment of laryngeal cancer resulted in the improvement of the 5-year survival rate in patients (12). In this regard, the studies showed that the survival rate of patients with laryngeal cancer is influenced by factors such as place of the tumor, stage and grade of disease, treatment type and age. Some studies have been carried out in Iran related to the survival rate of patients with laryngeal cancer aimed at promoting and improving treatment methods and investigating effective factors on survival rate $(10,13)$. As a result, more research is needed to increase the survival rate and quality of life for patients. Survival analysis is a set of statistical methods in which the response variable is the time to reach the given event. This event may refer to death, disease, improvement and etc. (14). Statistical modeling for investigation of the effective factors on the survival rate of patients is one of the goals of the survival analysis. Cox Proportional Hazard model is one of the most used models in survival studies. The Lin-Ying Additive Hazards Model is a well-known model, used less in survival analysis (15). In contrary to the Cox model estimating the hazard ratio, Lin-Ying additive model estimates the hazard difference (16).

In recent years, the incidence rate of cancer types, including laryngeal cancer, has increased. Therefore, the study on the survival rate of laryngeal cancer would determine the lethality of this disease and the treatment methods causing a higher survival rate. In recent years, no study has been conducted on the survival rate of laryngeal cancer in Kerman city as the greatest city located in the south-eastern part of Iran. This study was designed to study the effective factors on the survival rate of patients with laryngeal cancer in Kerman city. Also, considering that the Cox proportional hazards model and the Lin-Ying additive hazards model investigate the special aspects of patients' survival, both models were used in the present study.

\section{Methods}

\section{Study population}

This retrospective cohort study was conducted in Kerman province, the largest southeastern city of Iran. Subjects included 370 patients diagnosed with laryngeal cancer who referred to hospitals in Kerman city from 2008 to 2018. Patients' information was collected from their medical records and by making a phone call with them. Patients were followed up until June 2018 and their latest status was recorded.

The study variables included age at the time of diagnosis, gender, education, job, family history of any cancer, consumption of opium, consumption of smoking, and treatment type. In this study, individual occupational risktaking was defined based on the exposure to factors like asbestos, smoke, acid vapors, and dust. Occupations were divided into subgroups of riskless (like housewife, employee, and etc.), low-risk (animal husbandry, farmer, and etc.), risky (driver, worker, and etc.) and high-risk (mining and smelting factories staff, and etc.). Treatment of patients with laryngeal cancer was done by three ways including radiation therapy, chemotherapy, and surgery, or a combination of these methods.

Those who were alive until the end of the study (June 2018), were considered as the censored observations. The response variable was the period of time between the time of diagnosis of laryngeal cancer until death time or censor time, calculated based on the month. If the patient had died for any reason other than cancer, that patient was excluded from the study.

\section{Ethical issues}

The study protocol was approved by the Ethics Committee of Kerman University of Medical Sciences (Ethics code No: IR.KMU.REC.1397.202). The verbal consent was obtained by telephone from all participants, and the general objectives of the study and the potential re-used of the research data were told to the participants. We also confirmed that all methods were performed in accordance with the relevant guidelines and regulations.

\section{Statistical analysis}

In this study, the Kaplan-Meier method, Log-rank test, Cox proportional hazards, and Lin-Ying additive hazards models were used to analyze the data. In the Cox proportional hazards model, hazard ratio and a 95\% confidence interval were reported, and in Lin-Ying additive hazards model, excess risk and a 95\% confidence interval were reported. 
The univariate analysis was conducted for each model first. Then the variables with a p-value less than 0.20 were entered as important variables into the multiple models, and the final model was obtained using the backward method. Data analysis was done using SAS software version 9.4. A p-value of less than 0.05 was considered as statistically significant.

\section{Results}

Studied individual characteristics

Out of 370 patients with laryngeal cancer, 142 patients
$(38.88 \%)$ died. The mean follow-up duration of patients was $35.94 \pm 31.15$ months, and the range of duration was 119 months. The mean age at the diagnosis was equal to $58.16 \pm 10.60$ years old, and its range was 57 years old. Most of the patients were male $(91.08 \%)$. The number (percent) of alive patients, deaths and 1, 3 and 5- year survival rates of patients based on their characteristics are shown in Table 1.

Figure 1 shows the overall survival rate of cancer patients during 120 months of the study period. The mean survival time was $70.58 \pm 2.97$ months, and the median was equal to 82.03 months. The 1, 3, 5, 7 and 10-year overall

Table 1. Characteristics of patients $(\mathrm{n}=370)$ diagnosed with laryngeal cancer and 1, 3, and 5- year overall survival rates, Kerman, Iran, 2007-2017

\begin{tabular}{|c|c|c|c|c|c|c|}
\hline Characteristic & $\begin{array}{c}\text { Alive } \\
\mathrm{N}(\%)^{\mathrm{a}}\end{array}$ & $\begin{array}{c}\text { Dead } \\
\mathrm{N}(\%)^{\mathrm{a}}\end{array}$ & $\begin{array}{c}\text { Total } \\
n(\%)^{\mathrm{b}}\end{array}$ & $\begin{array}{l}1-\text { Year } \\
\text { OS }(\%)\end{array}$ & $\begin{array}{l}\text { 3-Year } \\
\text { OS }(\%)\end{array}$ & $\begin{array}{l}\text { 5-Year } \\
\text { OS (\%) } \\
\end{array}$ \\
\hline \multicolumn{7}{|l|}{ Age (year) } \\
\hline$\leq 57$ & $135(71.1)$ & 55 (28.9) & $190(51.3)$ & 88.02 & 67.93 & 65.20 \\
\hline$>57$ & $93(51.7)$ & $87(48.3)$ & $180(48.7)$ & 76.60 & 53.38 & 45.85 \\
\hline \multicolumn{7}{|l|}{ Gender } \\
\hline Female & $16(48.5)$ & $17(51.5)$ & $33(8.9)$ & 69.44 & 47.87 & 47.87 \\
\hline male & $212(62.9)$ & $125(37.1)$ & $337(91.1)$ & 83.71 & 62.08 & 56.99 \\
\hline \multicolumn{7}{|l|}{ Education level } \\
\hline$<$ High school & $144(59.3)$ & 99 (40.7) & $243(65.7)$ & 81.37 & 58.93 & 53.66 \\
\hline$\geq$ High school & $84(66.1)$ & $43(33.9)$ & $127(34.3)$ & 84.28 & 63.97 & 60.69 \\
\hline \multicolumn{7}{|l|}{ Job } \\
\hline No risk & $66(55.0)$ & $54(45.0)$ & $120(32.4)$ & 79.26 & 54.31 & 47.45 \\
\hline Low risk & $72(66.7)$ & $36(33.3)$ & $108(29.2)$ & 88.19 & 63.08 & 63.08 \\
\hline Risky & $63(64.9)$ & $34(35.1)$ & $97(26.2)$ & 77.80 & 60.53 & 60.53 \\
\hline High risk & $27(60.0)$ & $18(40.0)$ & $45(12.2)$ & 86.49 & 60.52 & 53.51 \\
\hline \multicolumn{7}{|l|}{ Family history of cancer } \\
\hline No & $154(61.8)$ & $95(38.2)$ & $249(67.3)$ & 83.66 & 61.34 & 54.97 \\
\hline Yes & $74(61.2)$ & $47(38.8)$ & $121(32.7)$ & 79.66 & 59.20 & 57.75 \\
\hline \multicolumn{7}{|l|}{ Smoking status } \\
\hline No & $31(52.5)$ & $28(47.5)$ & $59(16.0)$ & 75.82 & 57.88 & 51.55 \\
\hline Yes (only before diagnosis) & $147(69.7)$ & $64(30.3)$ & $211(57.0)$ & 88.92 & 69.40 & 64.79 \\
\hline Yes (before and after diagnosis) & $50(50.0)$ & $50(50.0)$ & $100(27.0)$ & 72.93 & 44.60 & 40.42 \\
\hline \multicolumn{7}{|l|}{ Opium abuse } \\
\hline No & $63(56.3)$ & $49(43.7)$ & $112(30.3)$ & 82.67 & 59.18 & 53.80 \\
\hline Yes (only Before diagnosis) & $127(66.8)$ & $63(33.2)$ & $190(51.3)$ & 86.44 & 64.45 & 61.00 \\
\hline Yes (before and after diagnosis) & $38(55.9)$ & $30(44.1)$ & $68(18.4)$ & 71.07 & 52.82 & 46.19 \\
\hline \multicolumn{7}{|l|}{ Radiotherapy } \\
\hline No & $20(38.5)$ & $32(61.5)$ & $52(14.1)$ & 64.87 & 41.40 & 38.73 \\
\hline Yes & $208(65.4)$ & $110(34.6)$ & $318(85.9)$ & 85.23 & 63.89 & 58.87 \\
\hline \multicolumn{7}{|l|}{ Chemotherapy } \\
\hline No & $81(71.7)$ & $32(28.3)$ & $113(30.5)$ & 84.05 & 73.57 & 67.94 \\
\hline Yes & $147(57.2)$ & $110(42.8)$ & $257(69.5)$ & 81.63 & 55.33 & 51.03 \\
\hline \multicolumn{7}{|l|}{ Surgery } \\
\hline No & $108(55.7)$ & $86(44.3)$ & 194 (52.4) & 74.38 & 55.04 & 49.96 \\
\hline Yes & $120(68.2)$ & $56(31.8)$ & $176(47.6)$ & 91.15 & 66.74 & 62.38 \\
\hline
\end{tabular}

OS Overall Survival; $(\%)^{\mathrm{a}}$ Row Percentage; $(\%)^{\mathrm{b}}$ Column Percentage

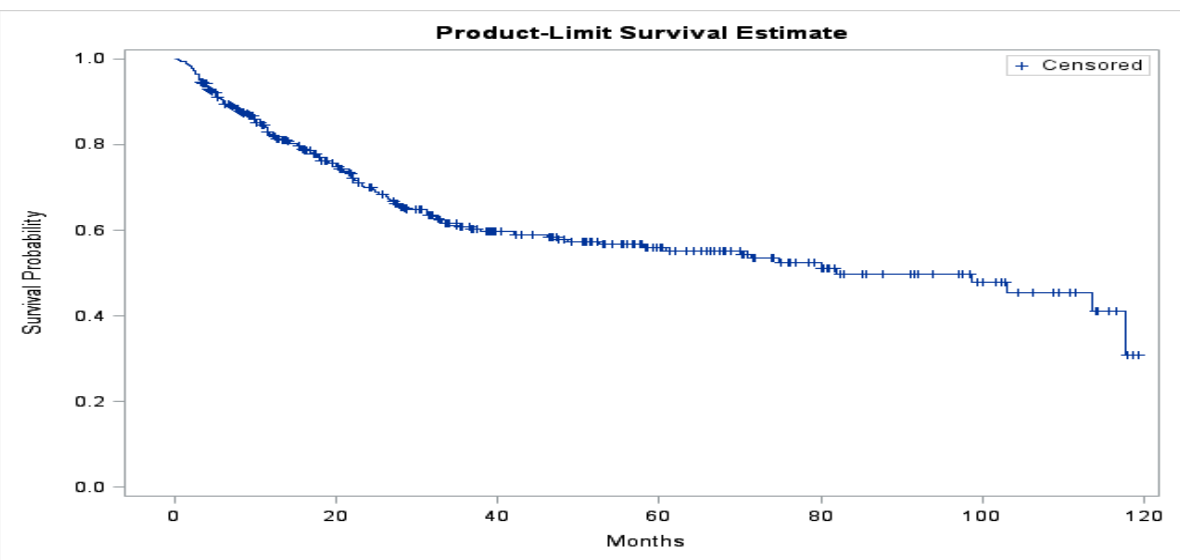

Fig. 1. Overall survival rate among patients diagnosed with laryngeal cancer, Kerman 2008-2018 
survival rates of patients were $82.38,60.68,55.98,49.83$ and $30.91 \%$, respectively.

The results of the comparison of survival rates in subgroups of variables using the log-rank test showed that age $(p<0.001), \quad$ radiotherapy $(p<0.001), \quad$ chemotherapy $(p=0.015)$, surgery $(p=0.005)$ and smoking $(p<0.001)$ had significant relationships with the survival rate of the patients, and gender $(p=0.076)$, education level $(p=0.187)$, family history of cancer $(p=0.761)$, job $(p=0.259)$ and consumption of opium $(\mathrm{p}=0.090)$ had no significant relationship with the survival rate of patients.

The number (percent) of alive patients, deaths, and 1, 3, and 5-year survival rates of patients based on the treatment type and combination of treatments are shown in Table 2. The highest 5- year survival rate was related to the combined method of treatment including the surgery and radiotherapy $(91.74 \%)$, and the lowest 5-year survival rate was related to the combined method of treatment including the surgery and chemotherapy $(31.17 \%)$.

\section{Cox proportional hazards model}

Table 3 shows the results of the Cox proportional hazards model in which age, smoking, radiotherapy, chemotherapy, and surgery were effective on the survival of patients. The results of the multiple analysis showed that the hazard of death in patients aged over 57 years was 1.90 times more than those under aged 57 years $(\mathrm{HR}=1.90$, $95 \%$ CI [1.34, 2.67], $\mathrm{p}<0.001)$. The hazard of death in patients who had a history of smoking before and after diagnosis of the disease was 1.91 times more than patients who smoked before the diagnosis of the disease $(\mathrm{HR}=1.91,95 \%$ CI $[1.29,2.81], \mathrm{p}=0.001)$. The hazard of death in patients with no history of smoking was 0.70 times less than patients who had a history of smoking before and after diagnosis of the disease $(\mathrm{HR}=0.70,95 \% \mathrm{CI}$ $[0.44,1.12], \mathrm{p}=0.141)$. The hazard of death in patients with no history of smoking was 1.33 times more than patients who smoked before the diagnosis of the disease $(\mathrm{HR}=1.33,95 \% \mathrm{CI}[0.84,2.13], \mathrm{p}=0.225)$. The hazard of death in patients received radiotherapy was 0.50 times less than patients who did not receive radiotherapy $(\mathrm{HR}=0.50$, $95 \%$ CI [0.33, 0.75], $\mathrm{p}=0.001)$. The hazard of death in patients received chemotherapy was 1.67 times more than patients who did not receive chemotherapy $(\mathrm{HR}=1.67$, 95\% CI [1.10, 2.52], $\mathrm{p}=0.020)$. The hazard of death in patients who underwent surgery was 0.68 times less than patients who did not undergo surgery $(\mathrm{HR}=0.68,95 \% \mathrm{CI}$ $[0.47,0.96], p=0.031)$. Gender, education level, job, family history of cancer and consumption of opium had no significant effect on the survival rate of patients $(\mathrm{p}>0.05)$.

Table 2. Characteristics of treatment type and 1,3, and 5-year overall survival rates

\begin{tabular}{lccccc}
\hline Treatment type & $\begin{array}{c}\text { Alive } \\
n(\%)^{\mathrm{a}}\end{array}$ & $\begin{array}{c}\text { Dead } \\
n(\%)^{\mathrm{a}}\end{array}$ & $\begin{array}{c}\text { Total } \\
n(\%)^{\mathrm{b}}\end{array}$ & $\begin{array}{c}\text { 1-Year OS } \\
(\%)\end{array}$ & $\begin{array}{c}3-\text { Year } \\
\text { OS }(\%)\end{array}$ \\
\hline without treatment & $5(55.6)$ & $4(44.4)$ & $9(2.4)$ & 64.81 & 51.85 \\
OS $(\%)$
\end{tabular}

S Surgery; RT Radiotherapy; CH Chemotherapy; CRT Chemoradiotherapy; OS Overall Survival; (\%) ${ }^{\mathrm{a}}$ Row Percentage; $(\%)^{\mathrm{b}}$ Colum Percentage

Table 3. The relationship between the study variables and laryngeal cancer using univariate and Multiple Cox Proportional Hazards Model

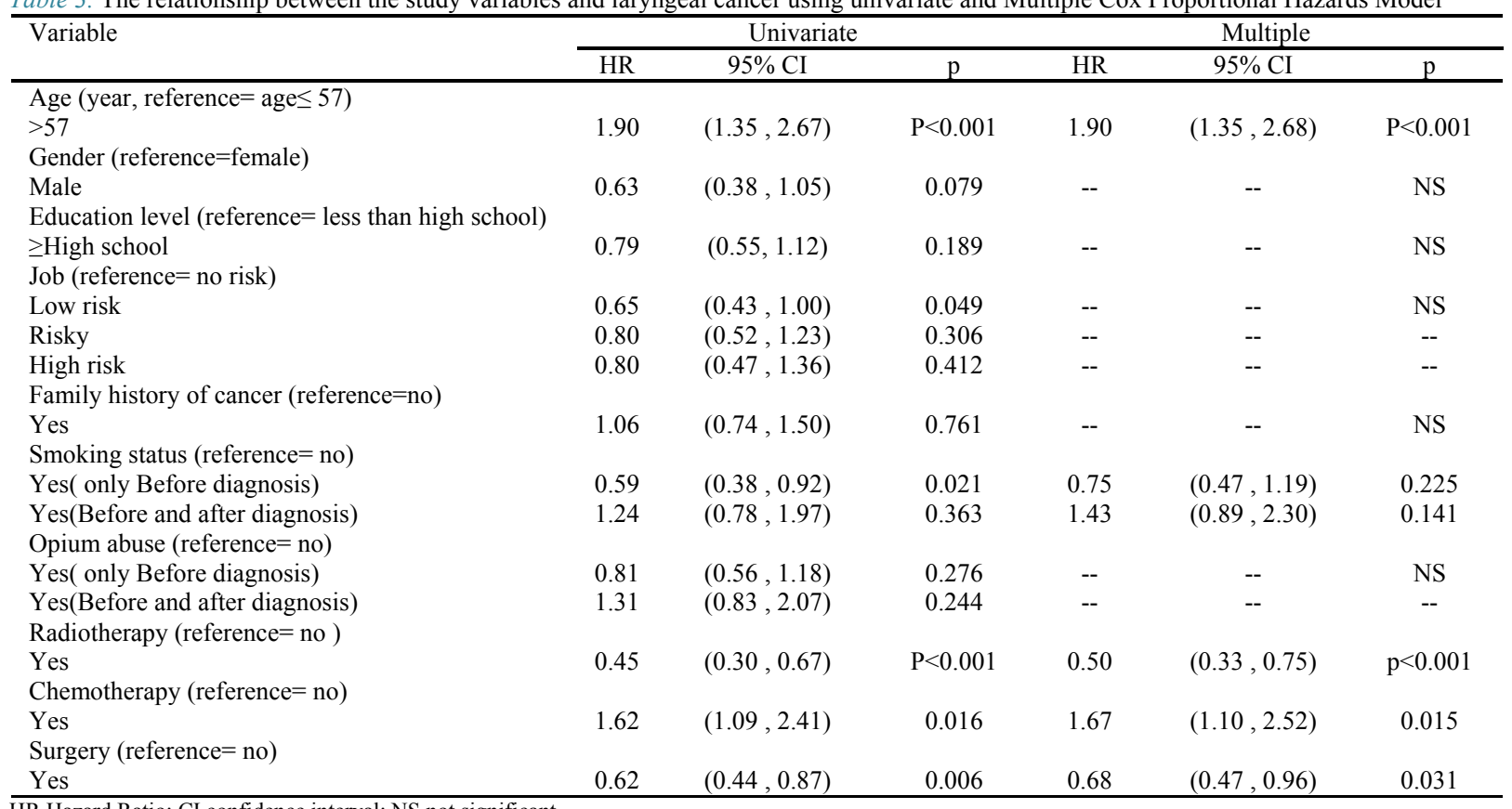

HR Hazard Ratio; CI confidence interval; NS not significant 


\section{Lin-Ying additive hazards model}

Table 4 illustrates the results of the Lin-Ying additive hazards model. The results revealed that age, smoking, radiotherapy, chemotherapy, and surgery were effective on the survival rate of patients. The patients aged over 57 years old showed a 0.007 increase in death hazard compared to patients aged under 57 years old $(E R=0.007,95 \%$ CI $[0.003,0.011], \mathrm{p}<0.001)$. The patients who had a history of smoking before and after the diagnosis of the disease showed a 0.008 increase in death hazard compared to patients who had a history of smoking before the diagnosis of the disease (ER=0.008, 95\% CI [0.002, 0.013], $\mathrm{p}=0.003$ ). The patients with no history of smoking showed a 0.005 decrease in death hazard compared to patients who had a history of smoking before and after diagnosis of the disease $(E R=-0.005,95 \%$ CI $[-0.012,0.002]$, $\mathrm{p}=0.180$ ). The patients with no history of smoking showed a 0.003 increase in death hazard compared to patients who had a history of smoking before the diagnosis of the disease $(E R=0.003,95 \%$ CI [-0.003, 0.008], $-p=0.307)$. The patients received radiotherapy showed a 0.009 decrease in death hazard compared to patients who did not receive radiotherapy $(\mathrm{ER}=-0.009,95 \%$ CI $[-0.017,-0.002]$, $\mathrm{p}=0.011)$. The patients received chemotherapy showed a 0.005 increase in death hazard compared to patients who did not receive chemotherapy $(\mathrm{ER}=0.005,95 \% \mathrm{CI}[0.001$, $0.009], \mathrm{p}=0.012$ ). The patients who underwent surgery showed a 0.004 decrease in death hazard compared to patients who did not undergo surgery $(E R=-0.004,95 \%$ CI [-0.008, -0.001], $\mathrm{p}=0.021)$. Gender, education level, job, family history of cancer, and consumption of opium had no significant effect on the survival rate of patients $(\mathrm{p}>0.05)$.

\section{Discussion}

This study investigated the effective factors on the survival rate of patients with laryngeal cancer using Cox proportional hazards and Lin-Ying additive hazards models.

In this study, the mean age at the diagnosis of patients with laryngeal cancer was equal to 58.2 years old. The results of other studies conducted in Iran showed the mean age at the diagnosis was 61.1 and 60.8 years old $(1,17)$. The results of a study carried out in the US showed that the mean age at the diagnosis was 57.2 years old (18). Therefore, it can be said that the prevalence of laryngeal cancer is high in higher ages, and it may occur due to the long-term effect of factors influencing this cancer, like the consumption of tobaccos.

In this study, most of the patients were men. In other studies conducted in Iran, such as studies by Jafari et al. and Daneshi et al. $92.1 \%$ and $95.9 \%$ of patients were male, respectively $(1,10)$. Also, about $90 \%$ of patients were male in studies conducted out of Iran $(19,20)$. The reason for the higher occurrence of laryngeal cancer in men is that men are probably more exposed to risk factors of laryngeal cancer. Men usually use more tobaccos, and high-risk jobs causing laryngeal cancer are done more by men, so more studies are required to study on the cause of the high prevalence of laryngeal cancer in men than women.

In this study, the mean survival time for patients with laryngeal cancer was equal to 70.6 months and the mean 5 -year survival rate of patients was equal to $55.9 \%$. In another study carried out in Iran (1), the mean 5-year survival rate of patients was found to be $57.7 \%$ which is consistent with the results of the present study. This is while in the studies conducted outside of Iran, the 5-year surviv-

Table 4. The relationship between the study variables and laryngeal cancer using univariate and Multiple Lin -Ying's Additive Hazards Model

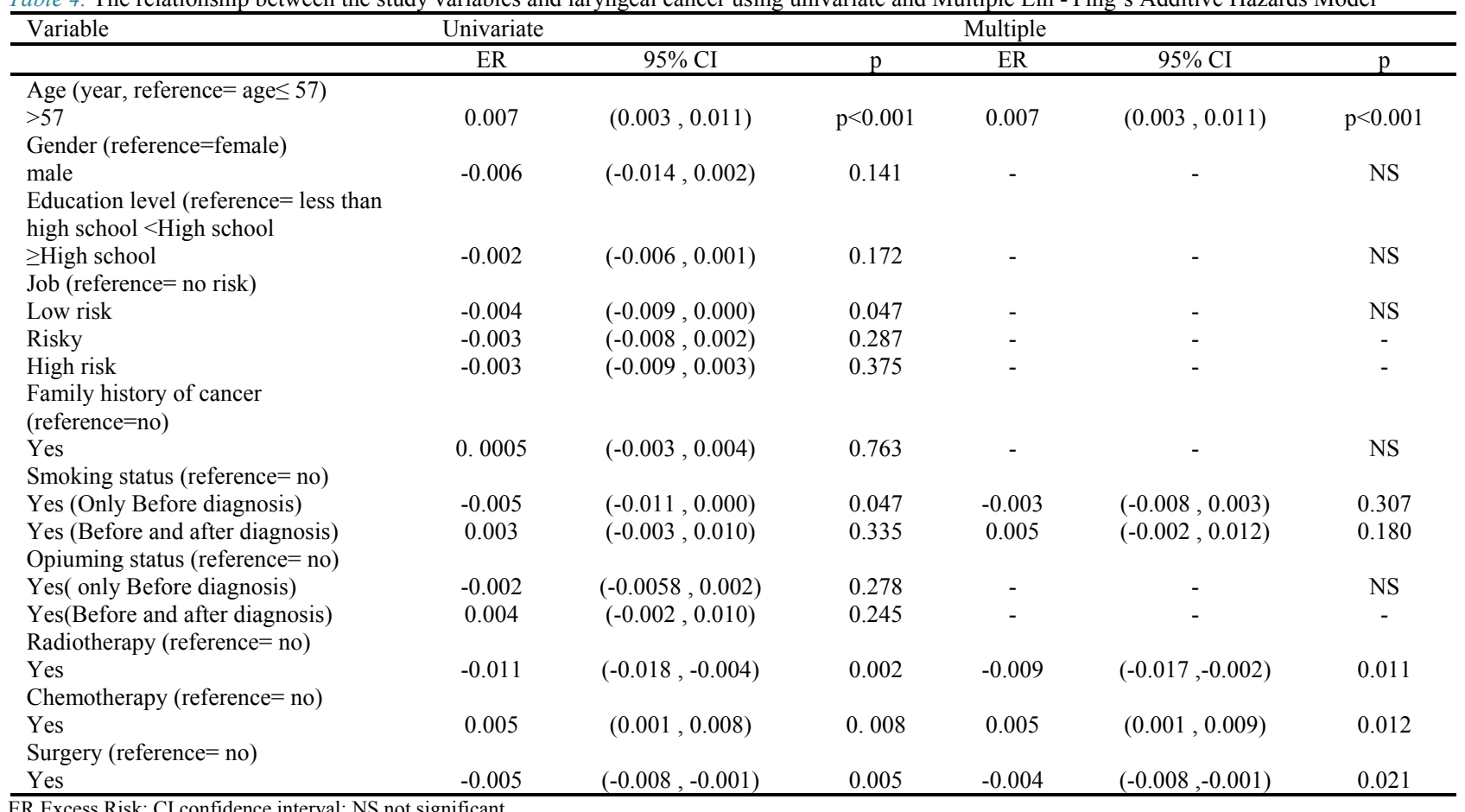


al rate was higher. For example, Francis et al. (21) and Ramroth et al. (19) in their studies showed that the 5-year survival rate of patients was $60 \%$ and $66 \%$, respectively. In the study done out of Iran, the 5-year survival rate of patients in the advanced disease was equal to $52 \%$ (22). The results of a study conducted in the south of Iran also showed that the 5-year survival rate of patients in the advanced disease was $53 \%$ which is consistent with the results of the foreign studies (10). The survival rate in different studies conducted throughout the world is less or more different and, the 5-year survival rate has been reported to be approximately 50 to 70 percent. Perhaps the reason for the difference in the results of the studies is dependent on factors such as diagnosis time, correct diagnosis of disease stage, proper and timely treatment, delay in the treatment, and patients' spirit and other factors.

The results of multiple analyses using Cox proportional hazards and Lin-Ying additive hazards models showed that age at the diagnosis, smoking, radiotherapy, chemotherapy, and surgery were effective on the survival of patients with laryngeal cancer. The results of the studies carried out in Iran and other countries showed that age was one of the most important risk factors for survival of patients with laryngeal cancer $(1,10,23,24)$. Therefore, it is concluded that with the increase in age, the death risk would also increase. Consequently, older patients need higher care.

Various studies have been conducted on therapeutic methods aimed at achieving the survival of patients with laryngeal cancer. In this study, patients who underwent surgery showed longer survival than patients who received radiotherapy and chemotherapy. In the studies by Daneshi et al., Megwalu et al., and wolf et al., patients who underwent surgery showed longer survival than patients who did not undergo surgery $(10,25,26)$. Although surgery is one of the most effective therapeutic methods used for achieving the survival of patients with laryngeal cancer, preserving the larynx is one of the concerns of patients. In fact, total laryngectomy influences the individual and social abilities of a person and would cause a reduction in the quality of life (10).

In this study, the 5-year survival rate of patients received radiotherapy was similar and slightly lower to those who underwent surgery. In the study by Timmermans et al. (27), patients who received radiotherapy were in T3; their 5-year survival rate was $47 \%$. In a study by Ian Ganly et al. (28) patients who received radiotherapy were in advanced disease; thier 5-year survival rate was $40 \%$. According to the results of these two studies, the patient's survival rate was found to be lower compared to the present study, which is logical since in the present study, all stages of the disease were considered.

Chemoradiation was identified as the most common therapy in this study. In most studies of chemoradiation was known as the most important therapy because it preserves the laryngeal and increases the quality of life of patients $(29,30)$. In this study of the 5-year survival rate of patients who received chemotherapy was lower than that of other methods, as well as chemotherapy was combined with each treatment method, which reduces the sur- vival rate; more likely, the patients who received chemotherapy had more advanced/aggressive disease. More studies are needed in this area to find the exact reason.

The results show, the combination of surgery and radiotherapy has the highest survival, which the disease level of these patients should be taken into account. Radiation therapy can only be an appropriate treatment but cannot guarantee the preservation of larynx performance. The results of this study show that the combination of radiation therapy with other treatments can lower the risk of death, so radiation therapy can be considered as a fixed base in the combination therapies. Overall, treatment is one of the most important factors affecting the survival of patients and more studies are needed to cover all the aspects of this field.

Results show smoking was effective on the survival of patients with laryngeal cancer. Patients who smoked prior to diagnosis were more likely to get cancer due to smoking, and cessation of smoking after diagnosis improved these patient's survival rates, which may be a reason for the higher survival rate of these patients in comparison to the other patients. Those patients who continued smoking after the diagnosis of cancer showed lower survival than the patients who stopped smoking after the diagnosis of the disease. Therefore, according to the results of this study, it is recommended for smokers to stop smoking to increase their survival rate. In other studies, smoking was not found to affect survival, which may be due to the different grouping of cigarette smoking in this study with other studies $(28,31,32)$.

The positive and strong point of this study included that; it investigated the death hazard of patients from two viewpoints. Cox proportional hazards model reports the death hazard ratio and the Lin-Ying additive hazards model reports the death excess risk in relation to the independent variables. Each of these models covers different aspects of data.

\section{Study Limitations}

Unfortunately, information about stage, grade, and tumor size was not accurately recorded for most patients. Consequently, these factors were not mentioned in the study.

\section{Conclusion}

Two models of Cox proportional hazard and Ling-Ying additive hazard are different in some aspects; therefore, the use of these two models covers the different aspects of data. In both models, age, smoking, and type of treatment had a significant effect on the survival of patients. High age would lead to a reduction in the survival rate as well as an increase in the death risk. Therefore, older patients need more care. Smoking after the diagnosis of cancer is not recommended because smoking was found to increase the risk of death. Treatment is an important factor in controlling the disease and survival of cancer patients, and choosing the best treatment depends on the condition of the patient and the disease level. As a result, further researches are needed to improve the quality of life and life expectancy of patients by choosing the most proper treat- 
ment methods.

\section{Acknowledgment}

This study was the output of an MSc thesis. We are grateful to Kerman University of Medical Sciences. We would like to express our gratitude to all personnel and patients of the teaching hospitals in Kerman, as well as Kerman University of Medical Sciences who helped in doing this study.

\section{Conflict of Interests}

The authors declare that they have no competing interests.

\section{References}

1. Jafari A, Gholizadeh N, Ramezani R, Razavi HE, Najafi S. Evaluation of survival rate in patients with laryngeal cancer. J Dent Med. 2017;30(2):89-96.

2. Bray F, Ferlay J, Soerjomataram I, Siegel RL, Torre LA, Jemal A. Global cancer statistics 2018: GLOBOCAN estimates of incidence and mortality worldwide for 36 cancers in 185 countries. CA Cancer J Clin. 2018;68(6):394-424.

3. The International Agency for Research on Cancer. 2019 [cited 17 Jan 2019]. Available from: https://gco.iarc.fr/today/online-analysis-table

4. Abachizadeh K, Keramatinia A. Anticipating cancer rates of Iran in 2025. Commonity Health. 2016;3(1):66-73.

5. Shahesmaeili A, Afshar RM, Sadeghi A, Bazrafshan A. Cancer Incidence in Kerman Province, Southeast of Iran: Report of an ongoing Population-Based Cancer Registry, 2014. Asian Pac J Cancer Prev. 2018;19(6):1533.

6. Emadzadeh M, Shahidsales S, Bajgiran AM, Salehi M, Massoudi T, Nikfarjam Z, et al. Head and neck cancers in North-East Iran: a 25year survey. Iran J Otorhinolaryngol. 2017;29(92):137-145.

7. Khoueir N, Matar N, Farah C, Francis E, Tabchy B, Haddad A. Survival of $\mathrm{T} 4 \mathrm{aN} 0$ and $\mathrm{T} 3 \mathrm{~N}+$ laryngeal cancer patients: A retrospective institutional study and systematic review. Am J Otolaryngol. 2015;36(6):755-762.

8. Bernier J, Bentzen SM. Radiotherapy for head and neck cancer: latest developments and future perspectives. Curr Opin Oncol. 2006;18(3):240-246.

9. Siegel R, DeSantis C, Virgo K, Stein K, Mariotto A, Smith T, et al. Cancer treatment and survivorship statistics, 2012. CA Cancer J Clin. 2012;62(4):220-241.

10. Daneshi N, Fararouei M, Mohammadianpanah M, Zare-Bandamiri M, Parvin S, Dianatinasab M. Effects of Different Treatment Strategies and Tumor Stage on Survival of Patients with Advanced Laryngeal Carcinoma: A 15-Year Cohort Study. J Cancer Epidemiol. 2018;2018:9678097.

11. Ma J, Liu S, Zhang W, Zhang F, Wang S, Wu L, et al. High expression of NDRG3 associates with positive lymph node metastasis and unfavourable overall survival in laryngeal squamous cell carcinoma. Pathol. 2016;48(7):691-696.

12. Wang W, Lin p, Han C, Cai W, Zhao X, Sun B. Vasculogenic mimicry contributes to lymph node metastasis of laryngeal squamous cell carcinoma. J Exp Clin Cancer Res. 2010;29(1):60.

13. Fararouei M, Daneshi N, Mohammadianpanah M, Tabatabaei HR, Zare-Bandamiri M, Dianatinasab M. Factors predicting survival in patients with early stage laryngeal cancer: A cohort study between 2000 to 2015. J BUON. 2017;22(4):996-1003.

14. Klein JP, Moeschberger ML. Survival Analysis Techniques for Censored and Truncated Data. 2003. 2nd Edition. Springer Publishers, New York.

15. Aalen OO. A linear regression model for the analysis of life times. Stat Med. 1989;8(8):907-925.

16. Xie X, Strickler HD, Xue X. Additive hazard regression models: an application to the natural history of human papillomavirus. Comput Math Methods Med. 2013; 2013:796270.

17. Gholizadeh N, Najafi S, Zadeh MK, Afzali S, Sheykhbahaei N. Trend in laryngeal cancer, mortality and survival rate in Iran. J Contemp Med Sci. 2018;4(1):7-11.

18. Scheel A, Bellile E, McHugh JB, Walline HM, Prince ME, Urba S, et al. Classification of TP53 mutations and HPV predict survival in advanced larynx cancer. Laryngoscope. 2016;126(9):E292-E299.

19. Ramroth H, Schoeps A, Rudolph E, Dyckhoff G, Plinkert P, Lippert $B$, et al. Factors predicting survival after diagnosis of laryngeal cancer. Oral Oncol. 2011;47(12):1154-1158.

20. Teppo H, Koivunen P, Hyrynkangas K, Alho OP. Diagnostic delays in laryngeal carcinoma: professional diagnostic delay is a strong independent predictor of survival. Head Neck. 2003;25(5):389-394.

21. Francis E, Matar N, Khoueir N, Nassif C, Farah C, Haddad A. T4a laryngeal cancer survival: retrospective institutional analysis and systematic review. Laryngoscope. 2014;124(7):1618-1623.

22. Rosenthal DI, Mohamed AS, Weber RS, Garden AS, Sevak PR, Kies MS, et al. Long-term outcomes after surgical or nonsurgical initial therapy for patients with T4 squamous cell carcinoma of the larynx: A 3-decade survey. Cancer. 2015;121(10):1608-1619.

23. Stokes WA, Jones BL, Bhatia S, Oweida AJ, Bowles DW, Raben D, et al. A comparison of overall survival for patients with T4 larynx cancer treated with surgical versus organ-preservation approaches: A National Cancer Data Base analysis. Cancer. 2017 123(4):600-608.

24. Shi X, Hu WP, Ji QH. Development of comprehensive nomograms for evaluating overall and cancer-specific survival of laryngeal squamous cell carcinoma patients treated with neck dissection. Oncotarget. 2017;8(18):29722-29740.

25. Megwalu UC, Sikora AG. Survival outcomes in advanced laryngeal cancer. JAMA Otolaryngol Head Neck Surg. 2014;140(9):855-860.

26. Wolf GT, Bellile E, Eisbruch A, Urba S, Bradford CR, Peterson L, et al. Survival rates using individualized bioselection treatment methods in patients with advanced laryngeal cancer. JAMA Otolaryngol Head Neck Surg. 2017;143(4):355-366.

27. Timmermans AJ, van Dijk BA, Overbeek LI, van Velthuysen ML, van Tinteren $\mathrm{H}$, Hilgers FJ, et al. Trends in treatment and survival for advanced laryngeal cancer: A 20-year population-based study in The Netherlands. Head Neck. 2016;38(S1):E1247-E1255.

28. Ganly I, Patel SG, Matsuo J, Singh B, Kraus DH, Boyle J, et al. Predictors of outcome for advanced-stage supraglottic laryngeal cancer. Head Neck. 2009;31(11):1489-1495.

29. Rodriguez CP, Adelstein DJ, Rybicki LA, Saxton JP, Lorenz RR, Wood BG, et al. Clinical predictors of larynx preservation after multiagent concurrent chemoradiotherapy. Head Neck. 2008;30(12):1535-1542.

30. Vengalil S, Giuliani ME, Huang SH, McNiven A, Song Y, Xu W, et al. Clinical outcomes in patients with T4 laryngeal cancer treated with primary radiotherapy versus primary laryngectomy. Head Neck. 2016;38(S1): E2035-E2040.

31. Kitani Y, Kubota A, Furukawa M, Hori Y, Nakayama Y, Nonaka T, et al. Impact of combined modality treatment with radiotherapy and S1 on T2N0 laryngeal cancer: Possible improvement in survival through the prevention of second primary cancer and distant metastasis. Oral Oncol. 2017;71:54-59.

32. Wichmann G, Krüger A, Boehm A, Kolb M, Hofer M, Fischer M, et al. Induction chemotherapy followed by radiotherapy for larynx preservation in advanced laryngeal and hypopharyngeal cancer: Outcome prediction after one cycle induction chemotherapy by a score based on clinical evaluation, computed tomography-based volumetry and 18F-FDG-PET/CT. Eur J Cancer. 2017;72:144-155. 